Original Research Article

\title{
Role of vitamin D supplementation as adjunctive therapy to escitalopram in patients of major depressive disorder: a 8 week prospective, randomized, interventional, clinical study
}

\author{
Shivangna Singh ${ }^{1 *}$, Priyamvada Sharma ${ }^{1}$, Vivek Gautam ${ }^{2}$
}

\begin{abstract}
${ }^{1}$ Department of Pharmacology, FHMC, Agra, Uttar Pradesh, India

${ }^{2}$ Department of General Medicine, SNMC, Agra, Uttar Pradesh, India
\end{abstract}

Received: 17 May 2019

Accepted: 02 July 2019

\section{*Correspondence to:}

Dr. Shivangna Singh,

Email: vivu25gtm@gmail.com

Copyright: (C) the author(s), publisher and licensee Medip Academy. This is an openaccess article distributed under the terms of the Creative Commons Attribution NonCommercial License, which permits unrestricted noncommercial use, distribution, and reproduction in any medium, provided the original work is properly cited.

\begin{abstract}
Background: Depression is a major public health problem and occurs in persons of all ages, and is associated with increased morbidity, soaring costs for treatment and reduced productivity and quality of life. Vitamin D is involved in numerous brain processes including neuroimmunomodulation, neuroprotection, neuroplasticity, regulation of neurotrophic factors, and making it biologically plausible to be associated with depression. Aim of the present study is to compare the therapeutic effects of vitamin D given along with escitalopram versus escitalopram given alone in patients with major depressive disorder.

Methods: In this prospective, randomized, interventional clinical study, 60 patients with a diagnosis of major depressive disorder based on ICD-10 criteria were randomly assigned into two groups, one group received 60000IU vitamin D3 weekly plus $10 \mathrm{mg}$ escitalopram OD daily while the other group received escitalopram10 mg OD daily alone for 8 weeks. Depression severity was assessed at 2-week intervals using the 24-item Hamilton Depression Rating Scale (HDRS). Serum $25(\mathrm{OH})$ vitamin D levels were measured in all the patients at baseline and after intervention.

Result: Fifty nine patients completed the trial. Depression severity based on HDRS decreased significantly after intervention, with a significant difference between the two groups. The vitamin D3+escitalopram combination was significantly better than escitalopram alone from the fourth week of treatment. Conclusion: Role of vitamin D in mood disorder and its dietary supplementation is effective as an adjuvant treatment along with SSRIs in depressive disorders, especially in vitamin $\mathrm{D}$ deficient patients.
\end{abstract}

Keywords: Major depressive disorder, Selective serotonin reuptake inhibitor, Vitamin D3

\section{INTRODUCTION}

Depression is a major public health problem and associated with significant disability, mortality and healthcare costs. It is projected that depression will become leading cause of disease burden and morbidity by 2030. ${ }^{1}$ Vitamin D is a unique neurosteroid hormone that may have an important role in the development of depression. Receptors for vitamin D are present on neurons and glia in many areas of the brain including the cingulate cortex and hippocampus, which have been implicated in the pathophysiology of depression. ${ }^{2}$
Vitamin D also regulates serotonin synthesis via transcriptional activation of the tryptophan hydroxylase gene and impacts innate immunity and the production of pro inflammatory cytokines that in turn influence mood by activating the stress response. Vitamin D is involved in numerous brain processes including neuroimmunomodulation, regulation of neurotrophic factors, neuroprotection, neuroplasticity and brain development making it biologically plausible that this vitamin might be associated with depression and that its supplementation might play an important part in the treatment of depression. ${ }^{2-5}$ 
Animal studies have confirmed the fundamental role of vitamin D in the development of the brain. ${ }^{6}$ Due to paucity of Indian data, we aimed to study the role of vitamin D3 as adjunctive therapy to escitalopram in patients of depression and to determine whether serum Cholecalciferol within the normal range could improve symptoms in such patients.

\section{METHODS}

A 8 weeks short term (March 2019 to April 2019) prospective, randomized, interventional, open label clinical study to evaluate the therapeutic effects of vitamin $\mathrm{D}$ as adjunctive therapy to escitalopram in patients with major depressive disorder was conducted in the Department of Pharmacology and Department of Psychiatry, FH Medical College and Hospital, Agra, Uttar Pradesh. Approval for the study was obtained from the Institutional Ethical Committee. Each subject signed an informed consent statement prior to participation and could withdraw without prejudice at any time.

Patients of age group 18-65 years and of both genders attending to psychiatry outpatient department during the study period diagnosed with first episode depression(drug naïve) as per criteria of the 10th edition of the International Classification of Diseases (ICD-10) along with hypovitaminosis $\mathrm{D}(<25 \mathrm{ng} / \mathrm{ml})$ were included in the study. Exclusion criteria included patients with history of taking antidepressants and vitamin D supplements before commencement of study, suffering from suicidal thoughts, substance abuse, patients taking any other psychiatric drug, pregnant and lactating mothers and patients suffering from renal, hepatic and cardiovascular disorders. A total of 60 patients comprised of sample size and by simple randomization they were divided into two groups (Group $\mathrm{A}=30$ \& Group $\mathrm{B}=30)$.Group $\mathrm{A}(\mathrm{n}=30)$ patients were given escitalopram 10mg/daily orally along with vit. D3 60000 IU weekly orally for 2 months. While Group B $(n=30)$ patients received only escitalopram $10 \mathrm{mg} /$ daily. No other psychiatric drug therapy was given to patients. Compliance was measured by counting escitalopram pills and measuring serum $25(\mathrm{OH}) \mathrm{D}$.

Analysis was performed on the 59 patients who completed the study. One patient was lost to follow-up from the fifth week of treatment in group B while no patient was lost in group A. A complete preliminary clinical examination was conducted on all subjects included in the study to rule out any chronic ailments referred to in the exclusion criteria. Socio- demographic data regarding age, sex, rural/urban, educational status and socio economic background were recorded in the case report form. Body weight, BMI, HDRS score and serum $25(\mathrm{OH})$ D levels were also recorded at baseline. Patients were subsequently monitored and reassessed after 2, 4, 6 and 8weeks. During each follow up visit HDRS score was evaluated and serum $25(\mathrm{OH}) \mathrm{D} 3$ levels were measured to compare with baseline values. Further, all adverse events at each visit or associated side effects during treatment were recorded in case report form. Statistical analysis of the data was performed by using the SPSS windows version 20. Mean values of change in HDRS score were compared between two groups by using unpaired ' $t$ ' test.

\section{RESULTS}

Demographic details of the enrolled patients are shown in the Table 1. Females suffering with depression were more as compared to males. Most of the depressive patients belonged to rural background and were illiterate having low socioeconomic status. There was no statistically significant difference between the two groups $(p>0.05)$, thus the groups were comparable.

Table 1: Demographic Details of Both the Groups.

\begin{tabular}{|llllll|}
\hline Parameters & Group A $(\mathbf{n}=\mathbf{3 0})$ & Group B $(\mathbf{n = 3 0})$ & Chi square value & P value \\
\hline Male/Female & $5 / 25$ & $3 / 27$ & 0.5769 & 0.44 \\
\hline Urban/Rural & $12 / 18$ & $10 / 20$ & 0.2871 & 0.59 \\
\hline Literate/Illiterate & $14 / 16$ & $13 / 17$ & 0.0673 & 0.79 \\
\hline Low socioeconomic status/middle class & $18 / 12$ & $15 / 15$ & 0.6061 & 0.43 \\
\hline
\end{tabular}

Table 2: Baseline Parameters of Both the Groups.

\begin{tabular}{|lllll|}
\hline Parameters & Group A & Group B & t value & P value \\
\hline Age $($ years $)$ & $40.45 \pm 5.65$ & $39.78 \pm 6.78$ & 0.0759 & 0.67 \\
\hline Body weight $(\mathrm{kg})$ & $68.35 \pm 4.31$ & $69.65 \pm 2.33$ & 0.2653 & 0.79 \\
\hline BMI $\left(\mathrm{kg} / \mathrm{m}^{2}\right)$ & $25.32 \pm 2.33$ & $26.12 \pm 3.78$ & 0.1802 & 0.85 \\
\hline Serum $25(\mathrm{OH}) \mathrm{D}(\mathrm{ng} / \mathrm{dl})$ & $20.65 \pm 1.78$ & $19.66 \pm 2.99$ & 1.5583 & 0.63 \\
\hline HDRS Score & $30.31 \pm 7.33$ & $31.65 \pm 7.35$ & 0.798 & 0.45 \\
\hline
\end{tabular}


Comparison of baseline values is shown in Table 2. There were no significant differences between the two groups with regard to age, body weight, body mass index (BMI), serum 25(OH)D3 and HDRS score $(\mathrm{p}>0.05)$. Moreover, the BMI did not change significantly during the intervention period $(p>0.05)$. Comparative evaluation of the HDRS score between the two groups is shown in Table
3. The serum $25(\mathrm{OH}) \mathrm{D}$ increased significantly in the Escitalopram+vitamin D3 group (A) from 20.65 \pm 1.78 to 40.85 $\pm 5.14(p<0.001)$. HDRS score values at weeks 2,4 , 6 and 8 showed that the vitamin D3-Escitalopram combination was significantly better than escitalopram alone from the fourth week of treatment $(\mathrm{p}=0.0007)$.

Table 3: Comparison of HDRS Score Between the Two Groups.

\begin{tabular}{|lllll|}
\hline HDRS Score & Group A & Group B & t value & P value \\
\hline Baseline & $30.21 \pm 7.33$ & $31.65 \pm 7.35$ & 0.7598 & 0.45 \\
\hline 2 weeks & $27.43 \pm 4.60$ & $27.23 \pm 4.60$ & 1.6843 & 0.097 \\
\hline 4 weeks & $19.43 \pm 4.76$ & $23.35 \pm 3.69$ & 3.564 & 0.0007 \\
\hline 6 weeks & $15.67 \pm 4.27$ & $20.00 \pm 2.37$ & 4.4904 & 0.0001 \\
\hline 8 weeks & $11.48 \pm 4.65$ & $18.25 \pm 3.17$ & 6.5889 & 0.0001 \\
\hline
\end{tabular}

\section{DISCUSSION}

The present study is a randomized, interventional, 8 weeks trial designed to determine the effects of vitamin D3 supplementation in patients with major depressive disorder, and we find that vitamin D3 is safe and effective as an adjunctive treatment to Escitalopram in major depressive disorder.

While there are few studies investigating the association between depression and vitamin D deficiency, but there is paucity of randomized controlled trial that can show beneficial effect of vitamin D3 with Escitalopram in mood disorders. ${ }^{7,8}$ In another open trial, it was shown that a single 300,000 IU dose of vitamin D3 could decrease depression severity in elderly patients with major depression. ${ }^{9}$ While other trial in older women has shown that a single annual dose of 500,000 IU of vitamin D3 for 3-5 years had no benefit on mood. ${ }^{10}$

Some Studies showed that serum levels of 25-hydroxyvitamin D3 in patients with mental disorders are significantly lower compared with healthy controls. ${ }^{11,12}$ Clinical studies show that people with high levels of vitaminD3 have a lower risk of depression. ${ }^{13}$ However; these findings are difficult to interpret, as reduced vitamin $\mathrm{D}$ could be a consequence of depressive behaviours. Vitamin D supplementation has been shown to relieve depressive symptoms in patients with low levels. ${ }^{14}$ It is important to note that these studies evaluated the effects of vitamin D supplementation alone, not compared with antidepressants.

The exact mechanism of how vitamin D is associated with depression is unclear. A number of mechanisms may involve in association of depression and low level of vitamin D. These include the vitamin D receptor and 1alpha-hydroxylase and vitamin D pathway components in neural differentiation, neuron function, neurotransmitter synthesis and inhibition of apoptosis and regulation of cell membrane formation. ${ }^{15,16}$

25-hydroxy-vitamin D3 can affect nerve growth factor, acetyl cholinesterase, tryptophan, testosterone, thyroid hormone and tyrosine hydroxylase messenger RNA synthesis, which are associated with depression. ${ }^{17}$ The classic monoamine neurotransmitter hypothesis suggests depression is associated with 5-HT, dopamine (DA) and norepinephrine (NE). It has been demonstrated that the expression of genes involved in the transfer of vitamin D affects nerves and stimulates the release of tyrosine hydroxylase, which plays a role in catecholamine biosynthesis. ${ }^{18}$ Vitamin D also improved the activity of glutathione in the cerebral cortex and striatum, and increased glutamate cysteine ligase (GCLM), glutathione reductase, which improved glutathione synthesis and played an important role in anti-oxidation. ${ }^{19}$ Thus vitamin D improves depression via suppressing antioxidant injury.

\section{CONCLUSION}

Authors can correlate role of vitamin D in mood disorder and its dietary supplementation is effective as an adjuvant treatment along with escitalopram in mood disorders, especially in vitamin D deficient patients. Vitamin D supplementation may be the most convenient and low-cost treatment method to improve the quality of life.

\section{ACKNOWLEDGEMENTS}

Our sincere gratitude to patients, their families, laboratory staff for their kind cooperation. Special thanks to Dr. Imran Zaheer, Dr. Arun Kumar Gupta \& Mr. Amit Kumar for patient recruitment and data intake.

Funding: No funding sources Conflict of interest: None declared

Ethical approval: The study was approved by the Institutional Ethics Committee 


\section{REFERENCES}

1. Mathers CD, Loncar D. Projections of global mortality and burden of disease from 2002 to 2030. PLoS Med. 2006Nov28;3(11):442.

2. Eyles DW, Smith S, Kinobe R, Hewison M, McGrath JJ. Distribution of the vitamin D receptor and1alphahydroxylase in human brain. J Chem Neuro Anat. 2005;29(1):21-30.

3. Patrick RP, Ames BN. Vitamin D hormone regulates serotonin synthesis. Part 1: relevance for autism. FASEB J. 2014Jun;28(6):2398-413.

4. Capuron L, Miller AH. Cytokines and psychopathology: lessons from interferon-alpha. Biol Psychiatry. 2004;56(11):819-24.

5. De Abreu DF, Eyles D, Feron F. Vitamin D, a neuroimmunomodulator: implications for neurodegenerative and autoimmunediseases. Psychoneuroendocrinology. 2009;34(Suppl 1):265-77.

6. Eyles DW, Feron F, Cui X. Developmental vitamin D deficiency causes abnormal brain development. Psychoneuroendocrinol. 2009;34:247-57.

7. Nayereh K, Mehdi TH . Therapeutic effects of vitamin $\mathrm{D}$ as adjunctive therapy to fluoxetine in patients with major depressive disorder. Australian NZ J Psychiatry. 2012;47(3):271-5.

8. Rebecca ES, Anglin, Zainab S. Vitamin D deficiency and depression in adults: systematic review and metaanalysis. The British J Psychiatry. 2013;202:100-7.

9. Zanetidou S, Murri MB, Buffa A. Vitamin D supplements in geriatric major depression. Int $\mathrm{J}$ Geriatric Psych. 2011;26:1209-10.

10. Sanders KM, Stuart AL, Williamson EJ. Annual highdose vitamin D3 and mental well-being: Randomised controlled trial. British J Psychiatry. 2011;198(5):357-64.

11. Robinson M, Whitehouse AJ, Newnham JP. Low maternal serum vitamin D during pregnancy and the risk for postpartum depression symptoms. Arch Womens Ment Health. 2014;17(3):213-9.

12. Williams JA, Romero VC, Clinton CM. Vitamin D levels and perinatal depressive symptoms in women at risk: a secondary analysis of the mothers, omega- 3 , and mental health study. BMC Pregnancy Childbirth. 2016;16(1):203.

13. Murphy PK, Wagner CL. Vitamin D and mooddisorders among women: An integrative review. J. Midwifery. Womens Health. 2008;53(5):440-6.

14. Vaziri F, Nasiri S, Tavana Z. A randomized controlled trial of vitamin $\mathrm{D}$ supplementation on perinatal depression: in Iranian pregnant mothers. BMC Pregnancy Childbirth. 2016;16:23-9.

15. McCann JC, Ames BN. Is there convincing biological or behavioral evidence linking vitamin $\mathrm{D}$ deficiency to brain dysfunction? FASEB. J. 2008;22(4):982-1001.

16. Garcion E, Wion-Barbot N, Montero-Menei CN. New clues about vitamin $\mathrm{D}$ functions in the nervous system. Trends. Endocrinol. Metab. 2002;13(3):100-5.

17. Eyles D, Cui X, Pelekanos M. Developmental Vitamin D Deficiency and Brain Dopamine Ontogeny. Schizophr. Res. 2010;117(2-3):169.

18. Sanchez B, Relova JL, Gallego R. 1, 25Dihydroxyvitamin D3 administration to 6hydroxydopamine-lesioned rats increases glial cell line-derived neurotrophic factor and partially restores tyrosine hydroxylase expression in substantia nigra and striatum. J. Neurosci. Res. 2009;87(3):723-32.

19. Jain SK, Micinski D. Vitamin D upregulates glutamate cysteine ligase and glutathione reductase and GSH formation and decreases ROS and MCP-1 and IL-8 secretion in high-glucose exposed U937 monocytes. Biochem. Biophys. Res. Commun. 2013;437(1):7-11.

Cite this article as: Singh S, Sharma $\mathrm{P}$, Gautam V. Role of vitamin D supplementation as adjunctive therapy to escitalopram in patients of major depressive disorder: a 8 week prospective, randomized, interventional, clinical study. Int J Basic Clin Pharmacol 2019;8:1713-6. 